Article

\title{
Coupled Delft3D-Object Model to Predict Mobility and Burial of Munition on Sandy Floor
}

\author{
Peter C. Chu ${ }^{1, *}$ Vinicius S. Pessanha ${ }^{1}$ and Chenwu Fan ${ }^{1}$ \\ 1 Department of Oceanography, Naval Postgraduate School, Monterey, California, USA \\ * Correspondence: pcchu@nps.edu
}

\begin{abstract}
Coupled Delft3D-object model has been developed to predict object's mobility and burial on sandy seafloor. The Delft3D model is used to predict seabed environment such as currents, waves (peak period, significant wave height, wave direction), water level, sediment transport, and seabed change, which are taken as the forcing term to the object model consisting of three components: (a) object's physical parameters such as diameter, length, mass, and rolling moment, (b) dynamics of rolling cylinder around its major axis, and (c) empirical sediment scour model with re-exposure parameterization. The model is compared with the observational data collected from a field experiment from 21 April to 23 May 2013 off the coast of Panama City, Florida funded by the Department of Defense Strategic Environmental Research and Development Program. The experimental data contain both objects' mobility using sector scanning and pencil beam sonars and simultaneous environmental time series data of the boundary layer hydrodynamics and sediment transport conditions. Comparison between modeled and observed data clearly show the model capability.
\end{abstract}

Keywords: Delft3D, Object Mobility Model, Munitions Mobility and Burial, Object Shields Parameter, Sediment Shields Parameter, Equilibrium Burial Percentage, Sediment Supporting Point

\section{Introduction}

The U.S. Army Corps of Engineers and the Navy have identified more than 400 underwater sites potentially contaminated with munitions [1]. Release of chemical elements from munitions are harmful to marine life and human health. Thus, an efficient model to forecast mobility and burial of munition on seabed can improve risk assessment and reduce costs related to remediation actions.

During the ONR accelerated research initiative (ARI) 2001-2005 "Mine Burial Prediction" [2], a physical model, called IMPACT35, was developed to predict the trajectory of a mine through air, water, and sediment to forecast the amount of burial that occurs upon impact with the seafloor [3][6]. IMPACT35 has six degrees of freedom (DoF), and is usually called a 6-DoF model. Three degrees of freedom refer to the position of center of mass of the object, and the other three degrees of freedom represent the orientation of the object (i.e., roll, yaw, and pitch). This model contains full physics including nonlinear dynamics, fluid-structure interaction, instability theory [7], and bearing factor method to calculate the sediment force and torque with cavities for mine movements in sediment [8].

Munition on seabed is less movable than sea mine in water column. Therefore, the existing 6DoF model (e.g., IMPACT35) for sea mine burial prediction needs to be modified. Also, the object model requires localized environmental parameters such as waves, currents, and sediment accretion/erosion in order to accurately predict the location, mobility, and burial of underwater munitions. When wind transmits momentum to the water surface, it may form waves that produce near-seabed orbital motion responsible for stirred-up sediment, and increase the sediment transport. 
In contrast, wave orbital motion in the company of currents intensifies the bed shear stress, and decreases the intensity of the current. Furthermore, the dissipation of wave energy in the surf zone induces currents along and across the shore. All the littoral flows carry a significant quantity of sediments. Predicting a munition's burial and mobility is a challenge considering all the processes involved. Recently, an object model was developed to predict munition's mobility and burial on the sandy seafloor using the observational environmental data (currents, waves, sediment, ...) as the forcing term [9].

An open source software, Delft3D, is available and capable to do so in nearshore areas [10-12]. Model output from Delft3D provides the neighboring environment required parameters to the 6-DoF model to predict a munition's burial and mobility. Under the sponsorship of SERDP, experimental [13-14] and analytical [15-16] studies focus on the determination of the conditions that determine the onset of a specific and important motion, i.e., roll of munition around its main axis, both on a hard surface and on a sand bed in the presence of concurrent scour burial.

In this study, a coupled Delft3D-object model has been developed to predict hydrodynamic and morphological processes as well as munitions' burial and mobility on the sandy sea floor. The Delft3D model output was taken as the forcing term for the object model. Figure 1 shows the flow chart of this coupled system. It consists of two major components: Delft3D and object model. The object model has four parts: (a) cylindrical object model with the burial percentage Shields parameter $\left(\theta_{o p b}\right),(b)$ sediment scour model with sediment Shields parameter $\left(\theta_{\text {sed }}\right)$, (c) input data such as object's physical parameters $\left(D, S_{0}, M, I_{0}\right)$, and environmental variables such as near seabed ocean currents, bottom wave orbital velocity $\left(U_{b r}\right)$ water depth $(h)$, wave peak period $\left(T_{P}\right)$, significant wave height $\left(H_{s}\right)$, sediment characteristics, and (d) model output such as the burial percentage $p_{B}$, and the object's displacement. The Target Reverberation Experiment 2013 (TREX13) in Panama City, Florida from 21 April to 23 May 2013 produced a unique data set containing environmental measurements such as waves, currents, and sediment accretion/erosion as well as mobility and burial of munitions [13]. The TREX13 data were used to verify the coupled model. The remainder of the paper is outlined as follows. Section 2 describes the observational data from TREX13. Sections 3-5 present the Delft3D, the object mobility model, and the object scour model. Section 6 presents prediction of the object's mobility and burial by the coupled Delft3D-object model. Section 7 presents the conclusions. Detailed object modeling information is included in Appendices A-D.

\section{Observational Data from TREX13}

Both environmental data (currents, waves, and seabed morphological change) and locations of surrogate munitions on the seafloor were simultaneously collected during the TREX13 from 21 April 2013 to 23 May 2013 at two sites [13]. The combined observations of munitions mobility and the driving environmental conditions provide data for model development and verification. Instruments were mounted on a pair of large rugged frames (herein referred to as "quadpods") that were deployed at two different water depths (herein referred to as "deep" and "shallow"). The quadpods deployed in the northern Gulf of Mexico offshore of Panama City Beach, Florida USA (Figure 2a). The deep quadpod was deployed at $30^{\circ} 03.02330 \mathrm{~N}, 85^{\circ} 41.33630 \mathrm{~W}$, in about $20 \mathrm{~m}$ water depth, while the shallow quadpod was deployed at $30^{\circ}$ $04.80994 \mathrm{~N}, 85^{\circ} 40.41064 \mathrm{~W}$, in about $7.5 \mathrm{~m}$ water depth. Waves and currents were obtained using both an acoustic surface tracking (Nortek AWAC) and pressure time series. A sector scanning sonar was mounted on one of the legs of each of the quadpods, scanning a $110^{\circ}$ swath every 12 minutes. 


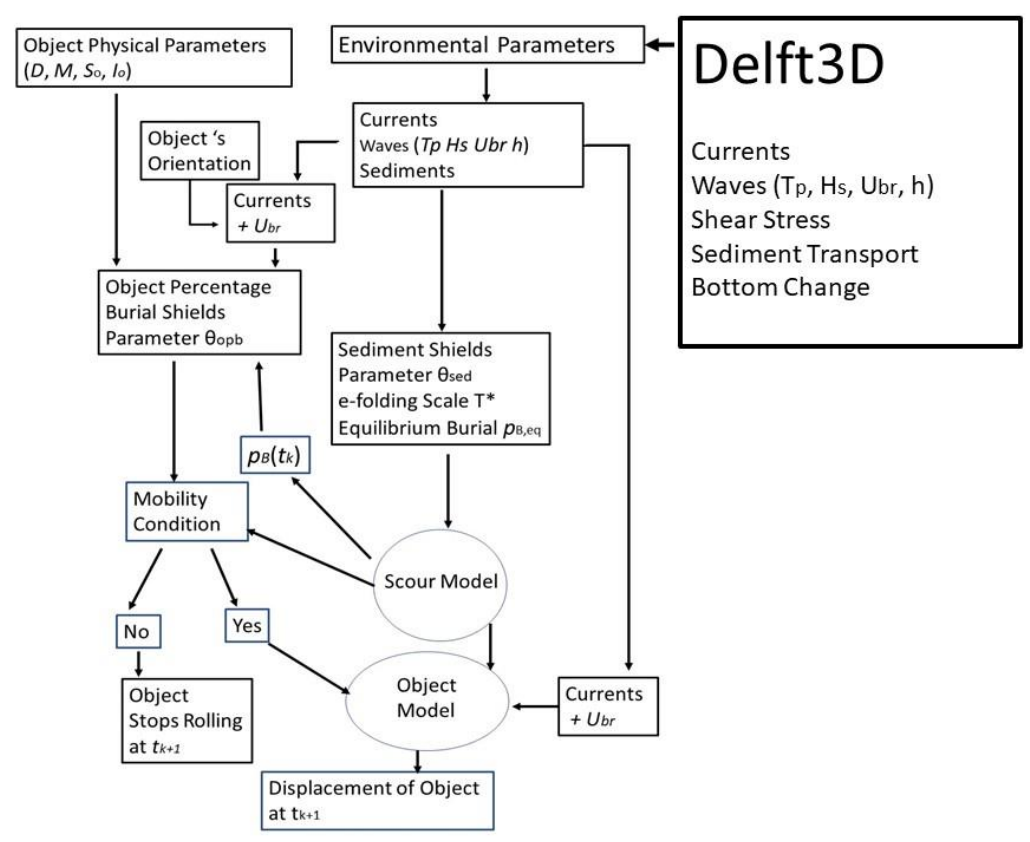

Figure 1. Flow chart of the coupled Dlft3D-object model to predict objects' mobility and burial.

At the same time, a range of surrogate munitions were deployed that include variations in caliber, bulk density, shape, and rolling moment. A total of 4 surrogate munitions and 9 replicas were deployed at each of two water depths adjacent to the quadpod instrument frames (Figure 3). Table 1 shows the complete list of deployed and recovered objects along with brief descriptions and their physical properties.

(a)

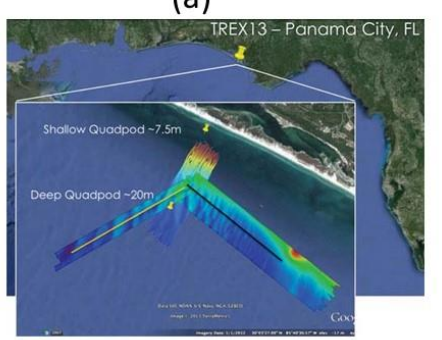

(b)

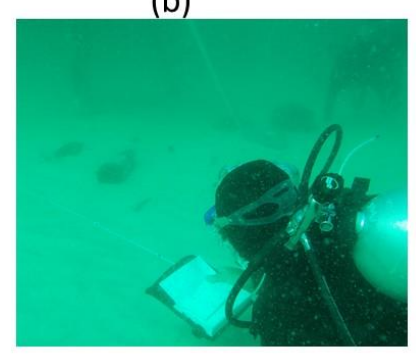

(c)

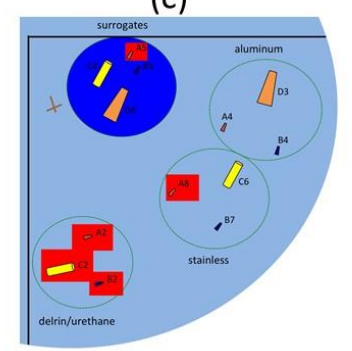

Figure 2. (a) locations of deep and shallow quadpods, (b) the photo of divers laying the object field during the shallow quadpod deployment, and (c) layout of objects laid by divers under the shallow quadpod (from [13]).
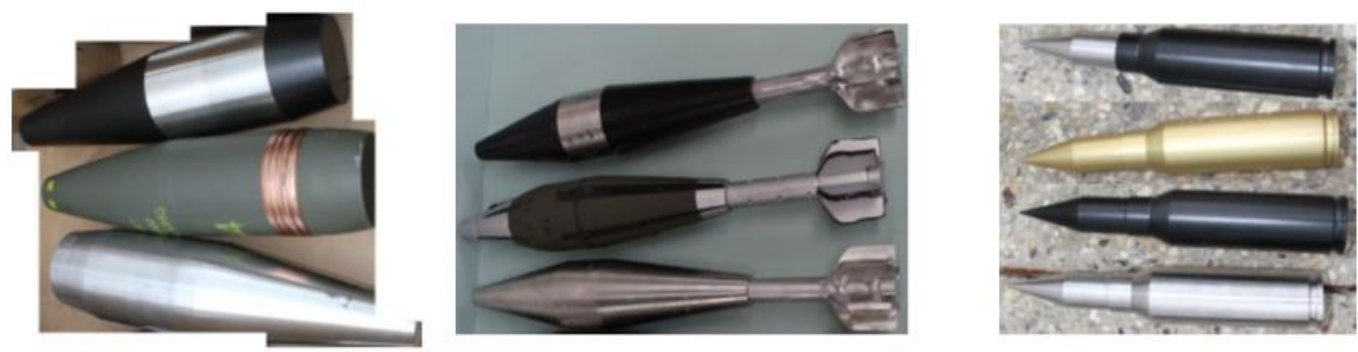

Figure 3. Fabricated surrogate, purchased replica, and fabricated replica of (left) $155 \mathrm{~mm}$ HE M107, (middle) $81 \mathrm{~mm}$ mortar, and (right) 25mm and $20 \mathrm{~mm}$ cartridges (from [13]). 
Table 1. List of surrogate and replica munitions used during TREX13. A total of 26 objects were deployed and 18 objects were recovered (from [13]). Type surrogate munitions were fabricated to have rolling moments within $10 \%$ of the estimated rolling moment of the real counterpart.

\begin{tabular}{|c|c|c|c|c|c|c|c|}
\hline $\begin{array}{l}\text { Type with } \\
\text { Diameter }\end{array}$ & Labels & $\begin{array}{l}\text { Materials } \\
\text { Type }\end{array}$ & Recovered & $\begin{array}{l}\text { Rolling } \\
\text { Moment } \\
\left(10^{-4} \mathrm{~kg} \mathrm{~m}^{2}\right)\end{array}$ & $\begin{array}{l}\text { Volume } \\
\left(10^{-5} \mathrm{~m}^{3}\right)\end{array}$ & $\begin{array}{l}\text { Mass } \\
(\mathrm{kg})\end{array}$ & $\begin{array}{l}\text { Density } \\
\left(\mathrm{kg} \mathrm{m}^{-3}\right)\end{array}$ \\
\hline \multirow[t]{2}{*}{$\begin{array}{l}155 \mathrm{~mm}, \\
\mathrm{HE}, \mathrm{M} 107\end{array}$} & D5, D6 & $\begin{array}{l}\text { Delrin, } \\
304 \text { Stainless } \\
\text { Surrogate }\end{array}$ & D5, D6 & 923.59 & 768.38 & 34.15 & 4,444 \\
\hline & D3, D4 & $\begin{array}{l}\text { Aluminum } \\
\text { Replica }\end{array}$ & D3, D4 & 500.48 & 768.38 & 20.91 & 2,721 \\
\hline \multirow[t]{3}{*}{$\begin{array}{l}81 \mathrm{~mm} \\
\text { mortar }\end{array}$} & $\mathrm{C} 3, \mathrm{C} 4$ & $\begin{array}{l}\text { Delrin, } 316 \\
\text { Stainless, } \\
\text { Aluminum } \\
\text { tail fins } \\
\text { Surrogate }\end{array}$ & $\mathrm{C} 3, \mathrm{C} 4$ & 24.73 & 120.93 & 3.76 & 3,109 \\
\hline & C5, C6 & $\begin{array}{l}304 \\
\text { Stainless, } \\
\text { Aluminum } \\
\text { tail fins } \\
\text { Replica }\end{array}$ & C5, C6 & 50.51 & 120.93 & 8.70 & 7,194 \\
\hline & $\mathrm{C} 1, \mathrm{C} 2$ & $\begin{array}{l}\text { Urethane } \\
\text { Replica }\end{array}$ & & 8.34 & 120.93 & 1.45 & 1,199 \\
\hline \multirow{4}{*}{$\begin{array}{l}25 \mathrm{~mm} \\
\text { cartridge }\end{array}$} & B5, B6 & $\begin{array}{l}\text { Delrin, } \\
316 \text { Stainless } \\
\text { Surrogate }\end{array}$ & B5, B6 & 0.46 & 16.55 & 0.39 & 2,356 \\
\hline & B7, B8 & $\begin{array}{l}304 \text { Stainless } \\
\text { Replica }\end{array}$ & B7, B8 & 1.98 & 16.55 & 1.32 & 7,975 \\
\hline & B3, B4 & $\begin{array}{l}\text { Aluminum } \\
\text { Replica }\end{array}$ & B3, B4 & 0.68 & 16.55 & 0.43 & 2,598 \\
\hline & B1, B2 & $\begin{array}{l}\text { Delrin } \\
\text { Replica }\end{array}$ & & 0.35 & 16.55 & 0.23 & 1,390 \\
\hline \multirow{4}{*}{$\begin{array}{l}20 \mathrm{~mm} \\
\text { cartridge }\end{array}$} & A5, A6 & $\begin{array}{l}\text { Delrin, } \\
316 \text { Stainless } \\
\text { Surrogate } \\
\end{array}$ & A6 & 0.13 & 7.70 & 0.20 & 2,597 \\
\hline & A7, A8 & $\begin{array}{l}304 \text { Stainless } \\
\text { Replica }\end{array}$ & A7 & 0.53 & 7.70 & 0.63 & 8,181 \\
\hline & $\mathrm{A} 3, \mathrm{~A} 4$ & $\begin{array}{l}\text { Aluminum } \\
\text { Replica }\end{array}$ & $\mathrm{A} 3, \mathrm{~A} 4$ & 0.18 & 7.70 & 0.19 & 2,468 \\
\hline & $\mathrm{A} 1, \mathrm{~A} 2$ & $\begin{array}{l}\text { Delrin } \\
\text { Replica } \\
\end{array}$ & & 0.09 & 7.70 & 0.11 & 1,429 \\
\hline
\end{tabular}


Divers laid the surrogate and replica munitions on the seafloor around shallow and deep quadpods within the view field of the sector scanning sonar on 21 April 2013 (Figure 2b). The location and orientation of surrogate and replica munitions were detected by the sector scanning sonar and maintenance diver with video camera. Only objects laid by divers under the shallow quadpod was photographed (Figure 2c). The field of view of the sector scanning sonar is roughly represented by the light blue. The locations of the surrogates are denoted by dark blue circle in the upper left. The other replicas were grouped according to relative bulk density. In this case the red boxes denote the objects that were not recovered from the shallow quadpod site. Thus, the initial surrogate munitions' location and orientation was provided from the TREX13 are only for the shallow quadpod.

\section{Delft3D}

\subsection{Model Description}

The open-source Delft3D version 4.04.01 was implemented in the TREX13 area to predict currents, waves, sediment transport, and morphological evolution. Under the wind and tidal forcing, the flow module predicts the currents, feeds the current data into the wave and morphology modules as input, computes the sediment transport, and updates the bathymetry. The flow module [10] uses uniform Chézy-type bottom roughness of $65 \mathrm{~m}^{1 / 2} \mathrm{~s}^{-1}$, horizontal eddy viscosity of $0.5 \mathrm{~m}^{2} \mathrm{~s}^{-1}$, and horizontal eddy diffusivity of $10 \mathrm{~m}^{2} \mathrm{~s}^{-1}$. The wave module [11] with the stationary mode is used to predict the wave generation, propagation, dissipation, and non-linear wave-wave interactions in the nearshore environment with inputs such as water level, bathymetry, wind, and currents from the flow module. The wave module uses Simulating Waves Nearshore (SWAN), which is a thirdgeneration model derived from the Eulerian wave action balance equation [12]. The coupling time between the flow and wave modules is set to 1 hour. The morphology module works in an integrated way with the wave and flow modules in a cycle. This system is a process-based model that considers the impact of waves, currents, and sediment transport on morphological changes.

\subsection{Model Grids and Time Steps}

Two grids with different grid cell sizes were nested (Figure 4) to create a region with finer resolution. These rectangular grids compose the flow domain. The flow outer grid (coarser resolution) is composed by $137 \times 75$ grid points spacing of $50 \mathrm{~m}$ both longshore and cross-shore directions. The flow inner grid (finer resolution) grid has $20 \mathrm{~m}$ resolution and was divided into $139 \mathrm{x}$ 124 grid points equally spaced. The sediment transport and morphological evolution were computed only in the flow inner grid to allow the comparison with TREX13 experiment measurements [17]. The wave domain (Figure 4) is defined in order to avoid the boundary effect and allow the use of deep quadpod data to set up the wave boundary conditions. The wave grid is composed by $273 \times 111$ grid points with $50 \mathrm{~m}$ resolution. The bathymetric data (Figure 4) used was from the Northern Gulf Coast Digital Elevation Model from the National Oceanic and Atmospheric Administration/National Geophysical Data Center (NOAA/NGDC) [18]. The resolution of this data set varies between 1/3 arcsecond and 1 arc-second (around 10 and $30 \mathrm{~m}$ ). The time step is set as $0.2 \mathrm{~s}$ for the coarse domain (grid size $50 \mathrm{~m}$ ) and $0.1 \mathrm{~s}$ for the finer domain (grid size $20 \mathrm{~m}$ ). 


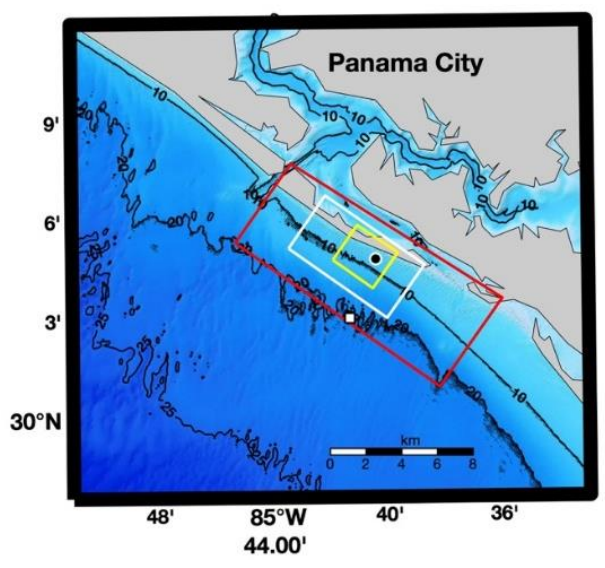

Figure 4. Bathymetry, depth contours (10 m, $20 \mathrm{~m}$, and $25 \mathrm{~m}$ ), wave (red), flow outer (white), and flow inner (yellow) computational grids enclosures are indicated on the map. The black dot represents the shallow quadpod location, and the white square denotes the deep quadpod location (from [17]).

\subsection{Wind and Tidal Forcing}

The wind input files were set up using the ERA5 Reanalysis data from the European Centre for Medium-Range Weather Forecasts (ECMWF), with $0.25^{\circ}$ (around $28 \mathrm{~km}$ ) resolution [19] for the flow and wave modules. The Global Inverse Tide Model TPXO 8.0, included in the DDB, was used to create the boundary conditions for the flow module. For the alongshore boundary, the water level with astronomic forcing was imposed. The water level gradient (a so-called Neumann boundary condition) was chosen with a constant zero water level slope in the longshore direction for both across-shore open boundaries. It allows for flow to leave and enter the lateral boundaries with no spurious circulation [20].

\subsection{Initial and Boundary Conditions}

As an initial condition, the water level was set to zero. Additionally, the sediment transport boundary conditions were set by specifying the inflow concentration as zero $\mathrm{kg} / \mathrm{m}^{3}$. The initial condition for the sand sediment was set as a uniform zero concentration, and the initial bed of sediment was set to $5 \mathrm{~m}$. Wave boundary conditions were set based on the measurements from the deep quadpod location using the significant wave height, wave period, wave directions, and directional spreading. These parameters were applied uniformly on the three open boundaries. The spin-up interval of 720 minutes was established to prevent any influence of a possible initial hydrodynamic instability on the bottom change calculation, which starts only after the spin-up interval. The sediment type was set as sand with a sediment-specific density of 2,650 kg/m

The calibration was directed to adjust the parameters and allow a better agreement between the model output and measurements. To calibrate the model, water level, waves, and currents from model results were compared with observations. Measurements between 21 and 27 April present a significant variation in water level, waves, and currents. For this reason, this period was selected for calibration. During this process, parameters were adjusted separately. While one was fine-tuned, the others remained constant.

\subsection{Model Output}


The time resolution for the Delft3D output data is 1 hour. The output from the flow module includes the current velocity, $\mathbf{U}_{c}=\mathbf{i} v_{e}+\mathbf{j} v_{n}$, with $(\mathbf{i}, \mathbf{j})$ the unit vectors in longitudinal and latitudinal directions, and the mean water level $(h)$. Let $U_{c}=\left(v e^{2}+v n^{2}\right)^{1 / 2}$ be the current speed. The output from the wave module includes the wave peak-period $\left(T_{P}\right)$, significant wave height $\left(H_{s}\right)$, and wave direction. The bottom wave orbital velocity $\left(U_{b r}\right)$ results of interactions between surface waves and the seafloor. A well-established linear wave model with Matlab function [21] is used to calculate the bottom orbital velocity $U_{b r}$ with the water depth $(h)$, significant wave height $\left(H_{s}\right)$, and peak period $\left(T_{p}\right)$ (see Appendix $D$ in [21]). The bottom water velocity vector of combined current and waves is represented by $\mathbf{V}_{w}$ with $\left|\mathbf{V}_{w}\right|=U_{c}+U_{b r}$ and the orientation, $\psi=\tan ^{-1}\left(v_{n} / v_{e}\right)$. Figure 5 shows the time series of the environmental parameters $\left[v_{e}, v_{n}, U_{c}, h, T_{P}, H_{s}, U_{b r}\right]$ predicted by the Delft3D (left panels) and observed by the AWAC (right panels).
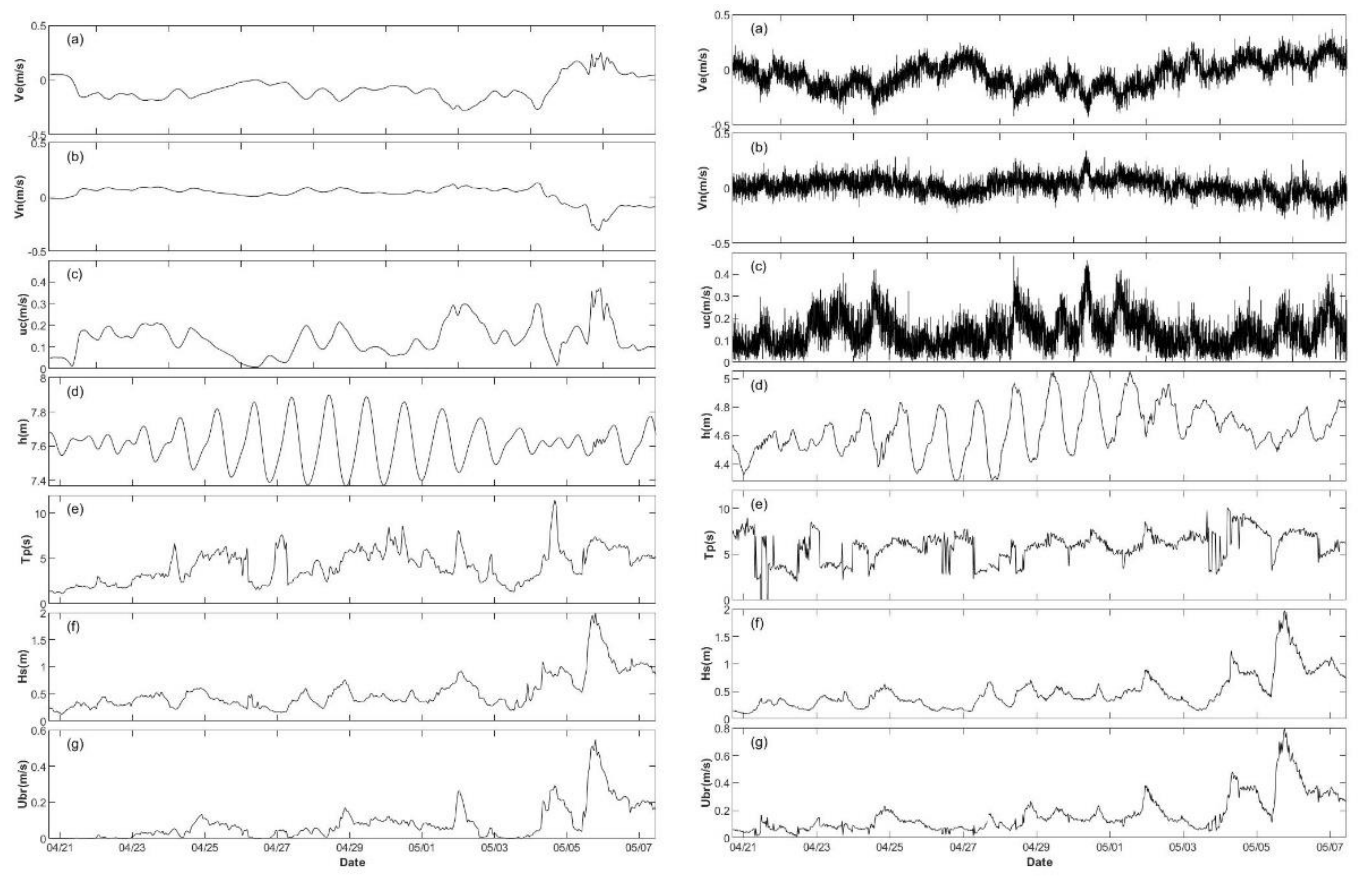

Figure 5. Comparison of Delft3D predicted (left panels) and observed during the TREX13 (right panels) at the shallow quadpod from 21 April to 7 May 2013: (a) near bed ( 0.15 m) longitudinal current $v_{e}(\mathrm{~m} / \mathrm{s})$, (b) near bed $(\sim 0.15 \mathrm{~m})$ latitudinal current $v_{n}(\mathrm{~m} / \mathrm{s})$, (c) near bed $(\sim 0.15 \mathrm{~m})$ current speed $U_{c}$, (d) water depth $h(\mathrm{~m})$ (mean water level plus quadpod 's height, $\left.2.3 \mathrm{~m}\right)$, (e) peak period $T_{P}$ (s), (f) significant wave height $H_{s}(\mathrm{~m})$, and (g) computed bottom wave orbital velocity $U_{b r}(\mathrm{~m} / \mathrm{s})$.

\section{Object Mobility Model}

Consider a cylindrical object with length $L$ and diameter $D$ buried in the seabed with the burial depth $B(B<D / 2)$. Let the water velocity (consisting current and waves) near the seabed ( $\left.\mathbf{V}_{w}\right)$ be in the direction towards the cylinder with an angle, $\phi$, perpendicular to main axis of the cylinder, and be decomposed into $\mathbf{V}_{w}=(U, V)$ with $U$ the perpendicular component, and $V$ the parallel component (Figure 6) to the main axis of the cylinder. As the object rolls with angular velocity $\omega$ on seabed with the object's burial let the axis of rotation inside the sediment be at depth $b(b<B)$ (see Appendix A). 


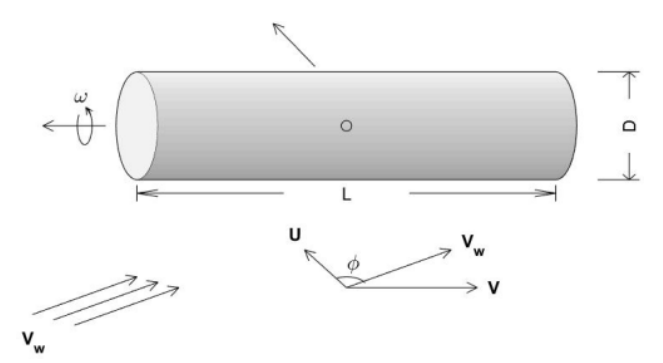

Figure 6. Roll of a cylindrical object on the seafloor with large aspect ratio forced by the combination of ocean currents and bottom wave orbital velocity. Here, $(\pi / 2-\phi)$ is the angle between $\mathbf{V}_{w}$ and the main axis of the cylinder.

As an object rolls around the point $b$ (see FigureA1 in Appendix A) with an angular velocity $\omega$, the translation velocity of the object is given by

$$
u_{o}=\omega\left(\frac{D}{2}-b\right)
$$

The corresponding moment of momentum equation of the rolling object is given by [see Eq.(B8) in Appendix B]

$$
\left\{\begin{array}{cc}
I_{A}^{*} \frac{d \omega}{d t}=T_{F}-\Pi\left(\rho_{o}-\rho_{w}\right) \sqrt{b(D-b)} & \text { if } p_{B}<0.5, \theta_{o p b}>1 \\
\omega=0, & \text { otherwise }
\end{array}\right.
$$

where $I_{A}^{*}=I_{o}+\rho_{o} \Pi D^{2} 4+(D / 2-b) \rho_{w} \Pi(D / 2+B / 2-b) ; I_{o}$ is the rolling moment of munition about the symmetric axis of the munition (see Figure B1); $T_{F}$ is the forward torque caused by the drag force $\left(F_{d}\right)$ and lift force $\left(F_{l}\right)$ (see Appendix $C$ ); $p_{B}=B / D$, is the percentage burial, and $\theta_{o p b}$ is the cylindrical object burial percentage Shields parameter with large aspect ratio (see Appendix B); $\left(\rho_{o}, \rho_{w}\right)$ are densities of object and water; $\Pi$ is the volume of the munition. Let the relative horizontal velocity of the rolling object be defined by

$$
\hat{u}_{o}=\frac{u_{o}}{U}
$$

Substitution of (1) into (2) and use of (3) lead to a special Riccati equation,

$$
\left\{\begin{array}{cc}
\frac{d\left(1-\hat{u}_{o}\right)}{d t}+\alpha\left(1-\hat{u}_{o}\right)^{2}=\beta, & \text { if } p_{B}<0.5, \theta_{o p b}(t)>1 \\
\hat{u}_{o}=0, & \text { otherwise }
\end{array}\right.
$$

where

$$
\begin{aligned}
& \alpha=\frac{\left(1-2 p_{b}\right)}{8 I_{A}^{*}} \rho_{w} C_{d}|U| D^{3} L\left[\left(1-p_{B}\right)\left(1+p_{B}-2 p_{b}\right)+2 \gamma \sqrt{p_{b}\left(1-p_{b}\right)}\right]>0 \\
& \beta=\frac{\left(1-2 p_{b}\right)}{2 I_{A}^{*}|U|} g \rho_{w} \Pi\left(S_{o}-1\right) D^{2} \sqrt{p_{b}\left(1-p_{b}\right)}>0
\end{aligned}
$$

The special Riccati equation (4) has an analytical solution from integration from $t_{k}$ to $t_{k}+1(k=0,1,2, \ldots, K-1)$ [22] 
$\hat{u}_{o}(t)=\left\{\begin{array}{c}\left\{\begin{array}{c}1-\frac{\left[1-\hat{u}_{o}\left(t_{k}\right)\right] \sqrt{\alpha_{k} \beta_{k}}+\beta_{k} \tanh \left[\left(\sqrt{\alpha_{k} \beta_{k}}\right)\left(t-t_{k}\right)\right]}{\sqrt{\alpha_{k} \beta_{k}}+\alpha_{k}\left[1-\hat{u}_{o}\left(t_{k}\right)\right] \tanh \left[\left(\sqrt{\alpha_{k} \beta_{k}}\right)\left(t-t_{k}\right)\right]}, \text { for } p_{B}\left(t_{k}\right)<0.5, \quad \theta_{o p b}\left(t_{k}\right)>1 \\ 0, \quad \text { for } p_{B}\left(t_{k}\right) \geq 0.5, \quad \theta_{o p b}\left(t_{k}\right) \leq 1, \quad t_{k}<t \leq t_{k+1}, \quad \alpha_{k}=\alpha\left(t_{k}\right), \quad \beta_{k}=\beta\left(t_{k}\right)\end{array}\right.\end{array}\right.$

with $\alpha_{k}$ and $\beta_{k}$ as known constants during the integration. Substitution of (6) into (3) leads to the dimensional horizontal velocity of the rolling object, $u_{\mathrm{o}}(t)=U \hat{u}_{o}(\mathrm{t})$, which should be used for each time interval $\Delta t$. The solution (6) depends on $\left(\alpha_{k}, \beta_{k}\right)$ which involve three types of parameters: (a) timeindependent physical parameters of the object for $S_{o}, \Pi, L$, and $D$; (b) time-dependent water velocity, $U\left(t_{k}\right)$, from Delft3D model output; (c) time-dependent relative depth of sediment rolling axis $\left[p_{b}\left(t_{k}\right)\right]$, and burial percentage $\left[p_{B}\left(t_{k}\right)\right]$ determined using a scour burial model. Let $l$ be the displacement of object,

$$
d l / d t=u_{o}
$$

Integration of $l$ with respect to time $t$ leads to the munition's displacement.

\section{Object Scour Model}

Existing studies on scour burial were all concentrated on motionless objects. The ratio between the fluid force (bottom shear stress) and the weight of the sediment particles, i.e., the sediment Shields parameter $\left(\theta_{\text {sed }}\right)$,

$$
\theta_{\text {sed }}=\frac{f U_{b r}^{2}}{g\left(S_{\text {sed }}-1\right) d_{50}}, S_{\text {sed }}=\frac{\rho_{s}}{\rho_{w}}, f=\exp \left[5.5\left(\frac{6 U_{b r} T_{P}}{\pi d_{50}}\right)^{-0.2}-6.3\right] \text {, }
$$

is crucial for scour burial of motionless object and in turn for prediction of the percentage burial parameter $p_{B}(t)$ $=B / D[15]-[16]$. Here, $f$ is the wave friction factor [23], $\rho_{s}$ the sediment grain density, and $d_{50}$ the medium sand grain size. Use of the wave data $\left(T_{P}, U_{b r}\right)$ from Figures. 6 e and $6 \mathrm{~g}$, and sediment parameters $\left(\rho_{s}=2.69 \times 103\right.$ $\left.\mathrm{kg} / \mathrm{m}^{3}, \quad d_{50}=0.23 \times 10^{-3} \mathrm{~m}\right)$ from the TREX13 [9], the sediment Shields parameter $\left(\theta_{\text {sed }}\right)$ are calculated from 21 April to 23 May 2013. It is less than 0.2 all the time except two atmospheric cold fronts passing by between 04 and 06 May 2013. The maximum value of $\theta_{\text {sed }}$ reached 0.61 (Figure 7).

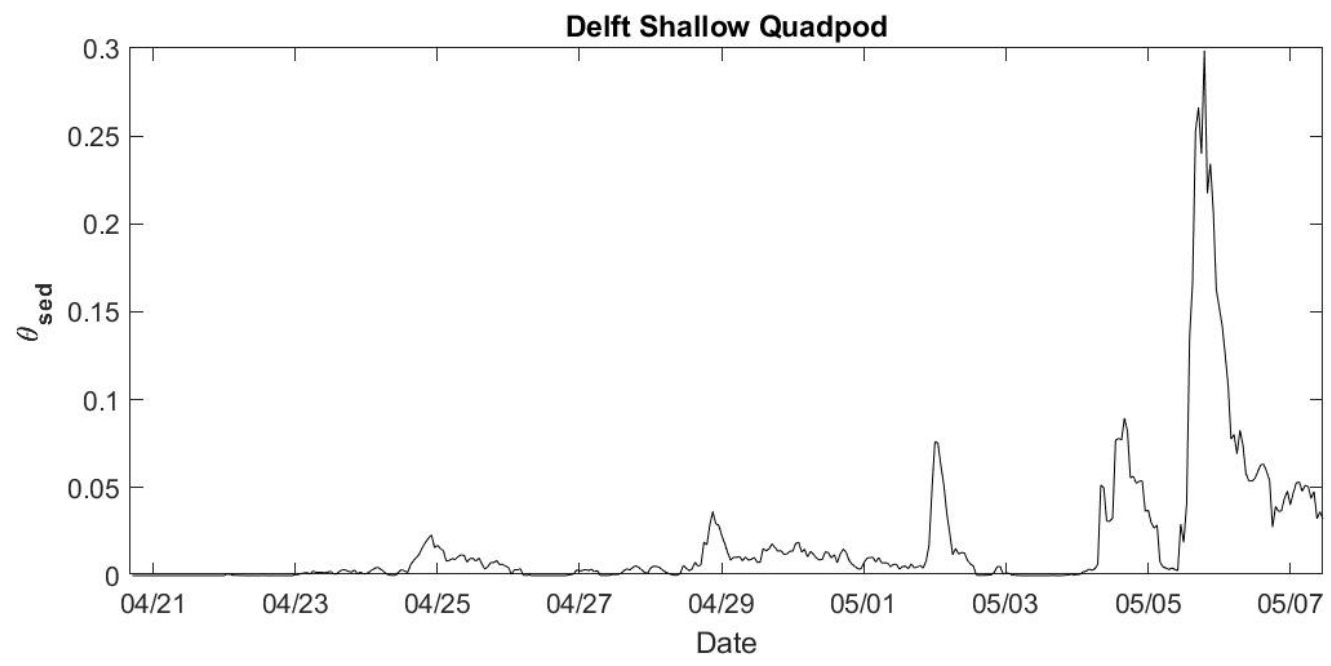

Figure 7. Time series of sediment Shields parameter $\left(\theta_{\text {sed }}\right)$ at the shallow quadpod computed from the Delft3D model output.

As pointed in [23], the equilibrium percentage burial $p_{B, e q}$ for motionless cylinders induced by scour tends to increase as $\theta_{\text {sed }}$ increases. An empirical formula has been established, 


$$
p_{B, e q}=a_{1} \theta_{\text {sed }}^{a_{2}}-a_{3}
$$

with different choices of the coefficients $\left(a_{1}, a_{2}, a_{3}\right)$ determined experimentally for cylinders subject to steady currents: $a_{1}=11, a_{2}=0.5, a_{3}=1.73$ [24], $a_{1}=0.7, a_{2}=a_{3}=0$ [25], $a_{1}=2, a_{2}=0.8, a_{3}=0$ [26], and for cylinders under waves (depending on wave period): $a_{1}=1.6, a_{2}=0.85, a_{3}=0$ for $T_{p}$ longer than $4 \mathrm{~s}$ [27]. For motionless cylinders before scour burial reaching equilibrium the percentage burial follows an exponential relationship $[24]$,

$$
p_{B}\left(t_{k}\right)=p_{B, e q}\left[1-\exp \left(-\frac{t_{k}}{T^{*}}\right)\right]
$$

where the e-folding time scale $T^{*}$ is given by

$$
T^{*}=\frac{c_{1} \theta_{s e d}^{c_{2}} D^{2}}{\left[g\left(S_{\text {sed }}-1\right) d_{50}^{3}\right]^{0.5}}, \quad c_{1}=1.5, \quad c_{2}=0.11 .
$$

With the bottom wave orbital velocity $\left(U_{b r}\right)$, sediment density $\left(\rho_{s}\right)$, medium grain size $\left(d_{50}\right)$, and in turn the sediment Shields parameter $\left(\theta_{\text {sed }}\right)$, the equilibrium object percentage burial $\left(p_{B, e q}\right)$ are calculated using (9) with coefficients $a_{1}=1.6, a_{2}=0.85, a_{3}=0$. The sediment supporting depth $b$ (or $p_{b}$ ) is calculated from burial depth $B$ (or $p_{B}$ ) using (10), i.e.,

$$
b\left(t_{k}\right)=\lambda B\left(t_{k}\right), p_{b}\left(t_{k}\right)=b\left(t_{k}\right) / D=\lambda p_{B}\left(t_{k}\right), \lambda=0.453
$$

It is noted that the predicted burial percentage $\left(p_{B}\right)$ computed from (10) represents the depth that an object on the surface would bury to at that moment. But an object deployed at the beginning of the time sequence would always remain buried at the deepest burial it has reached so far. The burial depth of the base of the object below the ambient seabed is equivalent to the greatest depth that the scour pit has reached up to that point in time [28]. In other words, scour only acts to bury an object deeper. It can never unbury (re-exposure) as the time series suggested by (10). Similar to [28], a simple parameterization was proposed [9] to represent the re-exposure process starting from $k(=1,2, \ldots)$ :

(a) doing nothing if $p_{B}\left(t_{k+1}\right) \geq p_{B}\left(t_{k}\right)$, (b) computing the weighted average

$$
\tilde{p}_{B}\left(t_{k+1}\right)=w p_{B}\left(t_{k}\right)+(1-w) p_{B}\left(t_{k+1}\right) \text { if } p_{B}\left(t_{k+1}\right)<p_{B}\left(t_{k}\right)
$$

with $w$ the weight coefficient. In this study, we take $w=0.80$. The object mobility and burial model consists of Eqs.(6)-(13).

\section{Prediction of Object's Mobility and Burial}

Munition's mobility and burial were predicted using the object mobility and burial models with the environmental variables predicted by the Delft3D (Figure 1) as the forcing term. The model was integrated for each surrogate (or replica) deployed in the shallow quadpod with its initial location and orientation (Figure 2c) from 12:40 (14:00) local time on 20 April 2013. The angle between $\mathbf{V}_{w}$ (data represented in left panels a, b, $g$ in Figure 5a) and the direction perpendicular to cylinder 's main axis is determined. The velocity vector $\mathbf{V}_{\mathrm{w}}$ is then transformed into $\mathbf{V}_{w}=(U, V)$ with $U$ the perpendicular component, and $V$ the paralleling component. The component $U$ is used in the model. The object 's physical parameters such as the diameter $(D)$, volume, mass $(M)$, and density $\left(\rho_{o}\right)$ are obtained from Table 1 .

The environmental data such as water depth $(h)$, wave peak period $\left(T_{P}\right)$, significant wave height $\left(H_{S}\right)$, bottom wave orbital velocity $\left(U_{b r}\right)$ (shown in the left panels in Figure 5), and sediment characteristics [Eq.(8)] are used for the scour model, i.e., Eqs(9)-(13), to get the burial percentage $p_{B}\left(t_{k}\right)$, and in turn the relative rolling 
center depth $p_{b}\left(t_{k}\right)$. With object's physical parameters $\left(D, \rho_{o}, M\right)$, calculated $p_{b}\left(t_{k}\right)$, model-predicted bottom current velocity component perpendicular to the object's main axis $U\left(t_{k}\right)$, coefficients $\left[\alpha\left(t_{k}\right), \beta\left(t_{k}\right)\right]$ for the object model [i.e., Eq.(5)], the object's displacement at the next time step $l\left(t_{k+1}\right)$ can be predicted using (7).

Based on the known initial locations of the objects at the shallow quadpod (Figure 2c), the model predicts the object's burial percentage $\left[p_{B}\left(t_{k}\right)\right]$ shown in Figure 8 , the object's percentage burial Shields parameter $\left[\theta_{o p b}\left(t_{k}\right)\right]$ shown in Figure 9, and the object's displacement $\left[l\left(t_{k}\right)\right]$ shown in Figure 10. The burial percentages $p_{B}$ for all the objects were less than 0.5 except during the storm event on 12:00 5 May to 00:00 6 May 2013 local time marked by two dotted lines (Figure 8). The red color in Figure 9 shows that the object 's rolling condition $\left[\theta_{o p b}>1\right]$ is satisfied.

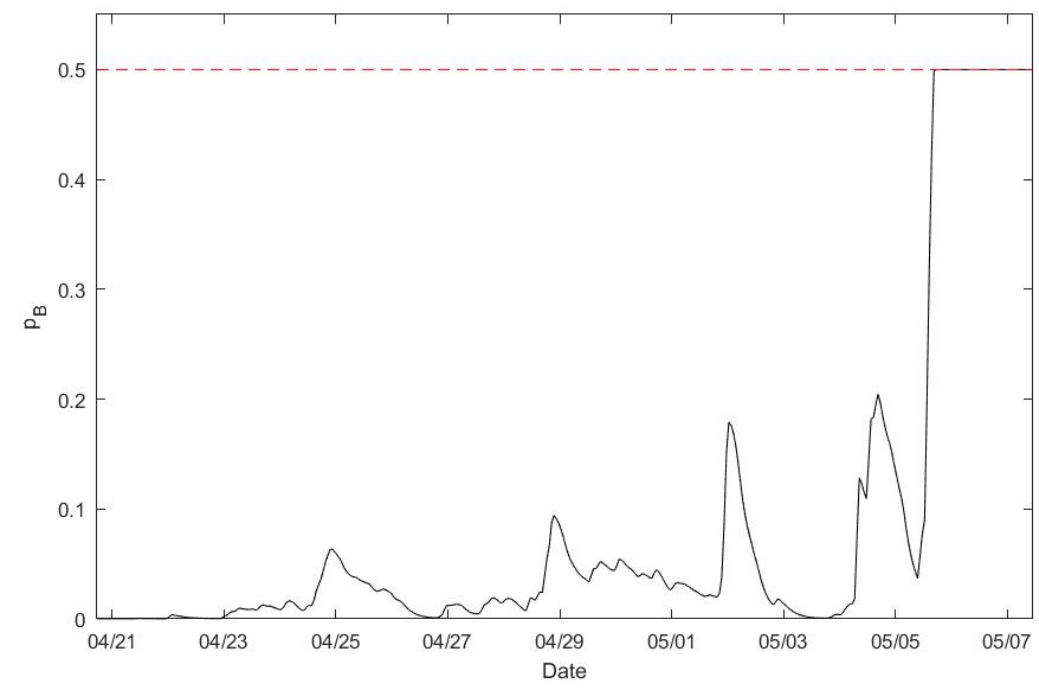

Figure 8. Model predicted burial percentage $p_{B}(t)$ with re-exposure parameterization (13) for each object at the shallow quadpod from 20 April to 7 May 2013. The predicted burial percentage $p_{B}(t)$ is less than 0.5 for all the munitions during the whole time period except during the storm event from 12:00 5 May to 00:00 6 May 2013.

The surrogate and replica munitions' mobility and burial were observed by divers and sector scanning sonar images during the field experiment depicted in Section 2 and in [13]. A total of 8 munitions in place at the shallow quadpod location were recovered by divers during the maintenance dive performed on 8 May 2013 (Figure 2b). Note that the munitions excavated by the divers at the shallow quadpod location on 8 May 2013 were immediately redeployed for the duration of the experiment. An overview of the observed munitions' mobility throughout the whole TREX13 experiment (20 April to 07 May 2013) is shown in Figure 11a, and during the storm event on 13:00-20:00 5 May 2013 in Figure 11b. Objects A2 and C2 were immediately mobile and transported out of the field of view because they were last seen on 23 April 2013. However, the other objects were almost not mobile (Figure 11a). The predicted objects' displacements (Figure 10) consist with the observations with large values of $15.1 \mathrm{~m}$ for A2 and $3.65 \mathrm{~m}$ for C2 on 12:00 24 April 2012, and with near zero for rest of the objects (Figure 10). Furthermore, overview of the modeled objects' mobility throughout the whole TREX13 experiment (20 April to 07 May 2013) is shown in Figure 11c, and during the storm event on 13:00-20:00 5 May 2013 in Figure 11d. Similarity between the observation (Figures. 12a, b) and the model prediction (Figures. $12 \mathrm{c}, \mathrm{d}$ ) shows model capability. 


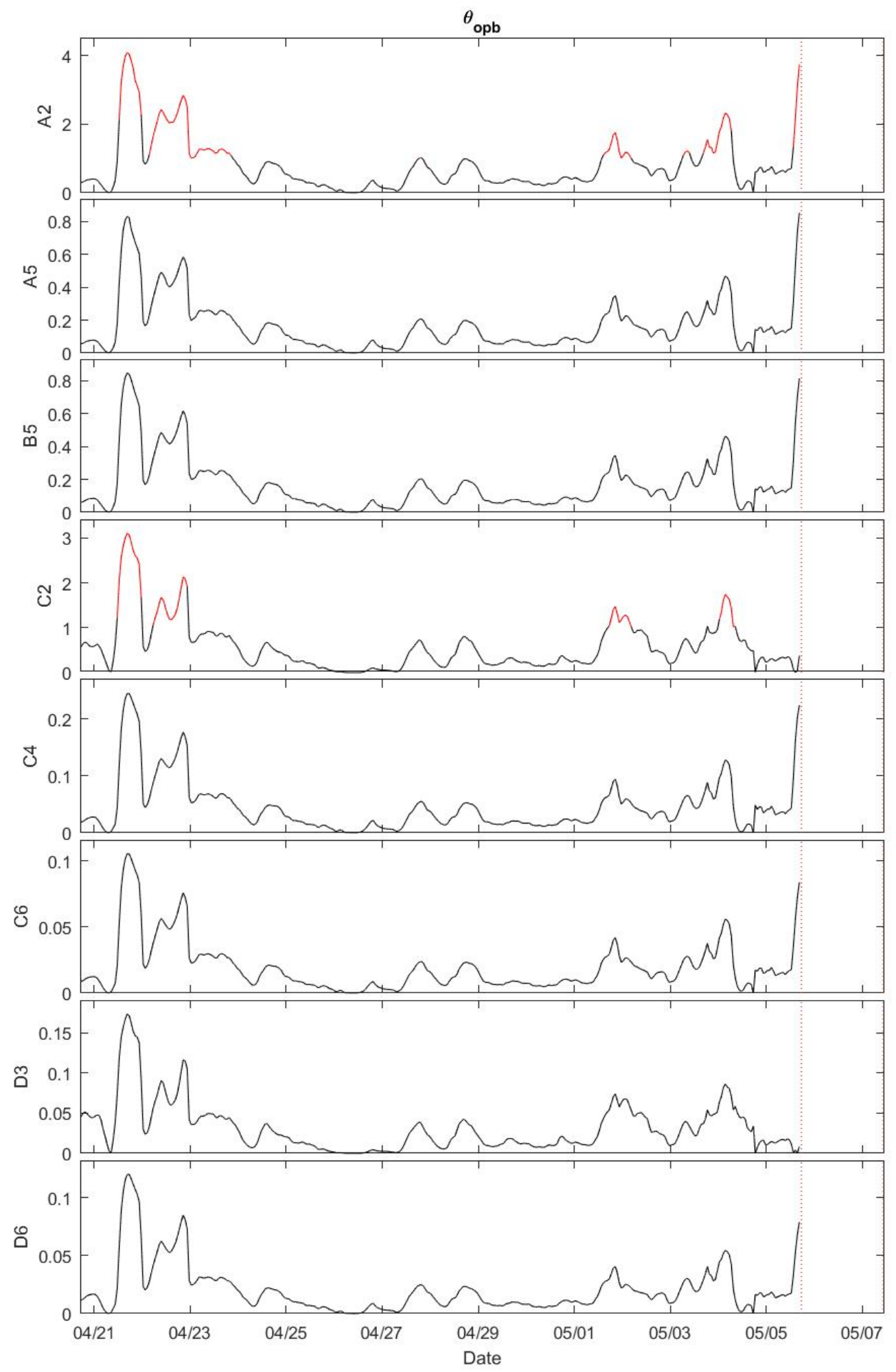

Figure 9. Model predicted object percentage burial Shields parameters $\theta_{o p b}$ at the shallow quadpod from 20 April to 7 May 2013. The red color shows that the condition for rolling the object $\left[\theta_{o p b}>1\right]$ is satisfied. The parameters $\theta_{o p b}$ is not computed between 12:00 5 May to 00:00 6 May 2013 since the predicted burial percentage $p_{B}(t)$ is larger than 0.5. Among the eight objects, only $\mathrm{A} 2$ and $\mathrm{C} 2$ have evident time periods that the condition for rolling the object $\left[\theta_{o p b}>1\right]$ is satisfied. 


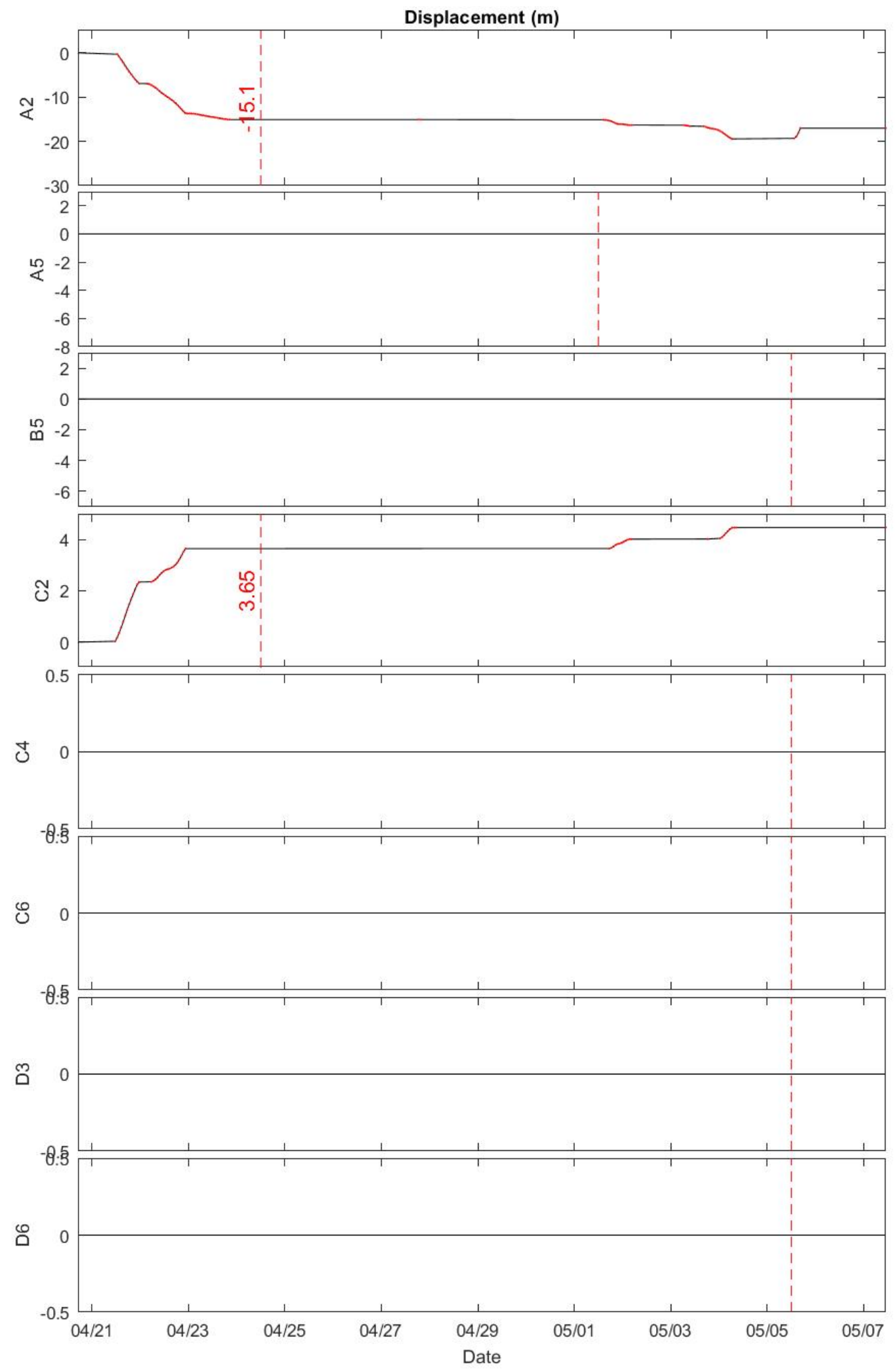

Figure 10. Model predicted displacement $l(t)$ for each object at the shallow quadpod from 20 April to 7 May 2013. Among the eight objects, only A2 and C2 were immediately mobile and displaced $15.1 \mathrm{~m}$ (A2) and 3.65 m (C2) on 12:00 24 April 2013 (dashed line); other munitions A5, B5, C4, C6, D3, D6 were completely motionless. 

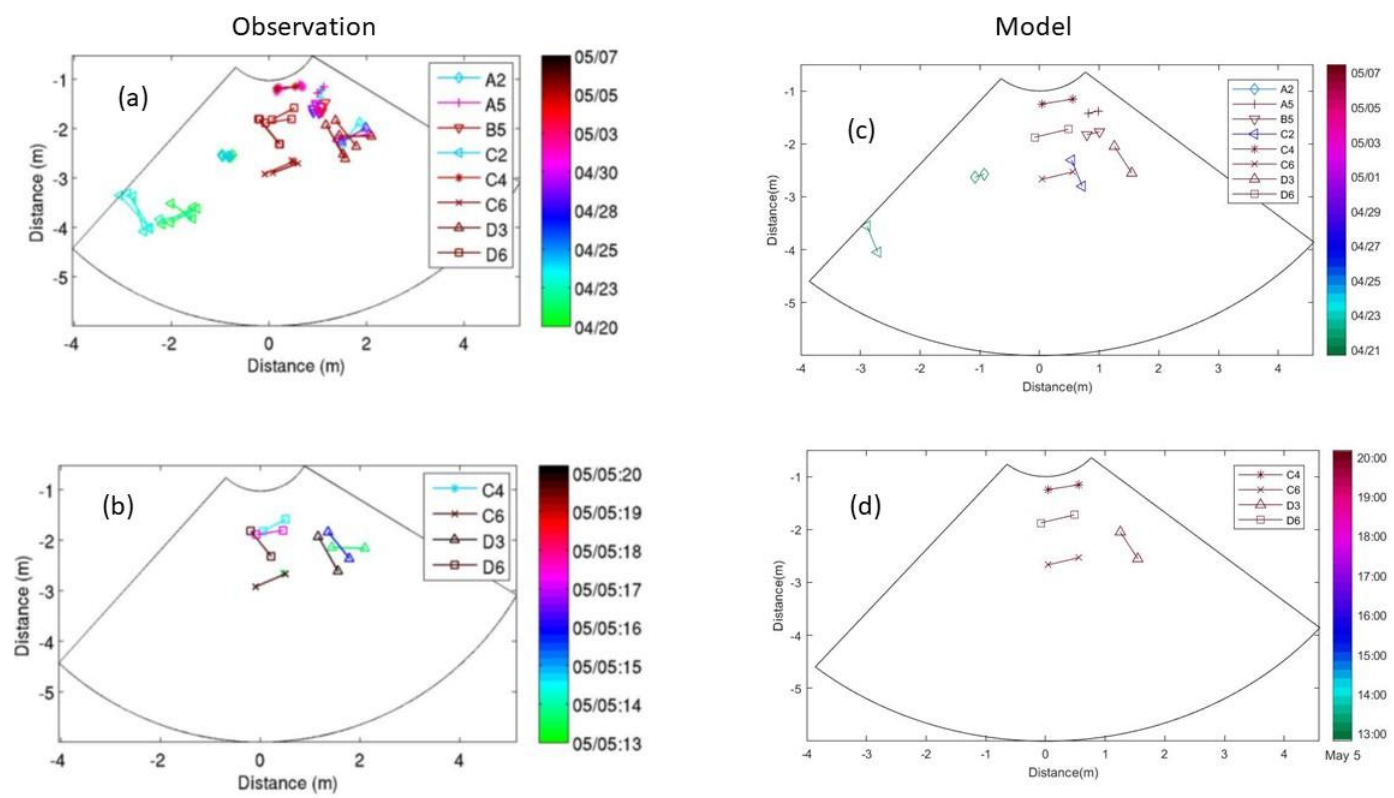

Figure 11. Positions for all visible objects at the shallow quadpod location up to the maintenance diver performed on 8 May: (a) observation for 20 April - 07 May 2013, (b) observation for 13:00-20:00 on 5 May 2013, (c) model prediction for 20 April - 07 May 2013, and (d) model prediction for 13:00-20:00 on 5 May 2013. Note that Figures. 14a and 14d were copied from [13]. The color bars denote the last time when each object was visible with dates for (a), (c) and hour on 5 May for (b) (d).

However, the model-data discrepancy shows the model limitation. For example, yaw of munitions D3 and D6 was observed (Figures 11a, b), but not predicted (Figures 11c, d). The munition D3 (rightmost triangles in Figures $11 \mathrm{a}, \mathrm{b})$ moved, and then moved back; so perhaps a net displacement of $0 \mathrm{~m}$ is correct, however the model predicted a value of $l=0 \mathrm{~m}$ by predicting that D3 never moved (Figures 10, 11c, d). The model limitation is due to the four assumptions such as (a) cylinder with large aspect ratio $(L \gg D)$, (b) no yaw and pitch, (c) percentage burial depth less than 0.5, and (d) flat seabed. Even if the bottom profile is flat when the object is deployed, the sand tends to accumulate in front of the object and to be eroded on the opposite side thus creating a wavy bed that affects the dynamics of the object. The model will lose capability in the real world if the shape of munition is evidently different from the cylinder with $L \gg D$ and the effect of wavy seabed is large on the dynamics of the object

\section{Conclusions}

(1) A coupled Delft3D-object model was recently developed to predict underwater cylindrical objects' mobility and burial in sandy bed, on the base of the results from SERDP sponsored projects such as MR-2224, MR-2227, MR-2319, and MR-2320, and ONR sponsored mine burial project. Roll of the object is the major dynamics of this model with a new concept of its rolling center in the sediment. The object's displacement caused by rolling satisfies the Riccati equation with analytical solution. Along with the dynamical model, the empirical scour model with re-exposure parameterization is used as part of the prediction system.

(2) Data collected at the shallow quadpod during TREX13 (21 April to 23 May 2013) off the coast of Panama City, Florida from the SERDP project MR-2320 were used as model verification. The environmental data such as bottom currents, water depth $(h)$, peak period $\left(T_{p}\right)$, and significant wave height $\left(H_{S}\right)$ are used to 
verify the Delft3D model. The objects' positions tracked by the sector scanning sonar images are used to verify the object's mobility and burial model. The predicted objects' positions agree qualitatively well with the observed surrogates (or replicas) data.

(3) Although the coupled Delft3D-object model predicts the object's mobility reasonably well, the model has its own weakness such as for cylindrical object only. Also, it only considers the roll of the cylinder around its major axis. The model ignores pitch and yaw. Besides, the seabed is assumed flat. It is necessary to extend the modeling effort to more realistic seabed environment, object shapes and more complete motion for operational use.

Author Contributions: For research articles with several authors, a short paragraph specifying their individual contributions must be provided. The following statements should be used "conceptualization, P.C.; methodology, P.C.; software, V.P., and C.F.; validation, P.C., V.P. and C.F.; formal analysis, P.C..; investigation, P.C.; resources, P.C.; data curation, V.P. and C.F.; writing-original draft preparation, P.C.; writing-review and editing, P.C.; visualization, V.P. and C.F.; supervision, P.C.; project administration, P.C.; funding acquisition, P.C."

Funding: This research was funded by the Department of Defense Strategic Environmental Research and Development Program (SERDP), grant numbers N6227C20WA00DCE and N6227C21WA00AWC. The APC was funded by the Research Office of the Naval Postgraduate School.

Acknowledgments: The authors would like to thank Dr. Joseph Calantoni at the Naval Research Laboratory at the Stennis Space Center for providing the TREX13 data.

Conflicts of Interest: The authors declare no conflict of interest.

\section{Appendix A Location of Object's Rotation Axis in Sediment}

Roll of an object on the sandy floor needs a supporting point in sediment. The compressive normal stress of sediment on the object is represented by

$$
\mathbf{F}_{s}=-\mathbf{n} \kappa u_{o} \sin \psi
$$

where $\mathbf{n}$ is unit vector normal to the cylinder surface, and $\kappa$ is the compressive coefficient. Let $\mathbf{n}$ be decomposed into

$$
\mathbf{n}=-\mathbf{e}_{h} \sin \psi-\mathbf{e}_{v} \cos \psi
$$

where $\left(\mathbf{e}_{h}, \mathbf{e}_{v}\right)$ are horizontal and vertical unit vectors (see Figure A1). The sediment compressive normal stress $\mathbf{F}_{S}$ is decomposed as,

$$
\mathbf{F}_{S}=\mathbf{e}_{h} \kappa u_{o} \sin ^{2} \psi+\mathbf{e}_{v} \kappa u_{o} \sin \psi \cos \psi
$$

With $b$ as the axis of rotation, the sediment above (below) the depth $b$ generates torque to resist (enhance) the rolling with the total torque from the sediment,

$$
\mathbf{T}_{S}=\int_{0}^{\psi_{B}}\left[\left(\mathbf{r}-\mathbf{r}_{b}\right) \times \mathbf{F}_{S}\right] d \psi=\int_{0}^{\psi_{B}}\left[\mathbf{r} \times \mathbf{F}_{S}\right] d \psi-\mathbf{r}_{b} \times \int_{0}^{\psi_{B}} \mathbf{F}_{S} d \psi,
$$

where $\mathbf{r}$ is the position vector at any point on the circle and $\mathbf{r} b$ is the position vector at point $b$ with point $E$ as the origin,

$$
\mathbf{r}=\frac{D}{2}\left(-\mathbf{e}_{h} \sin \psi+\mathbf{e}_{v}(1-\cos \psi), \quad \mathbf{r}_{b}=\frac{D}{2}\left[-\mathbf{e}_{h} \sin \psi_{b}+\mathbf{e}_{v}\left(1-\cos \psi_{b}\right)\right] .\right.
$$




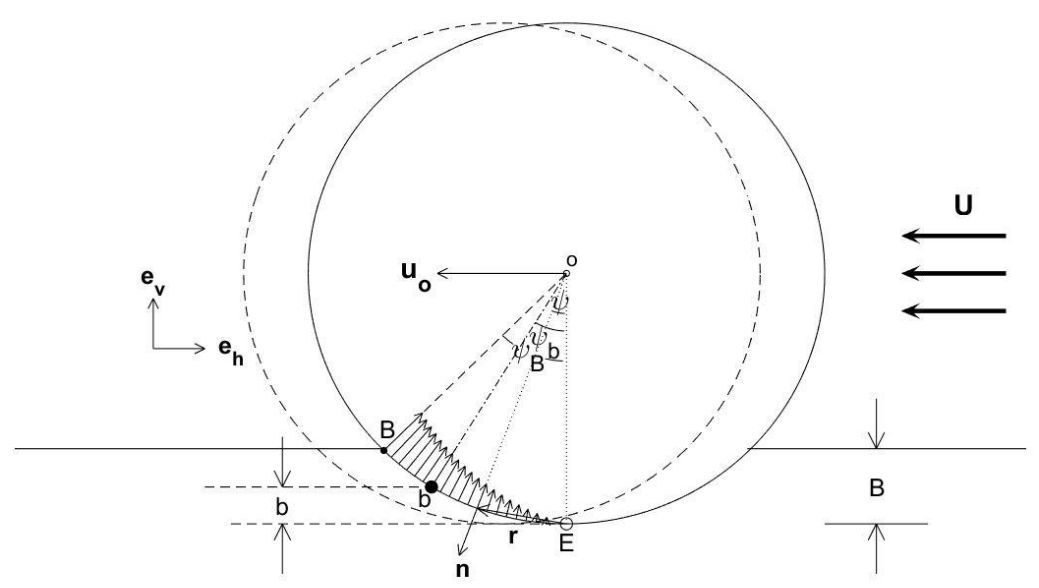

Figure A1. The location of the axis of rotation of the cylinder in the sediment, $b$, is determined by the assumption of zero-sum torque to the roll.

The depths $B$ and $b$ are represented by

$$
B=\frac{D}{2}\left(1-\cos \psi_{B}\right), \quad b=\frac{D}{2}\left(1-\cos \psi_{b}\right) .
$$

If we assume that at the depth $b$ the total torque from the sediment is zero (i.e., zero-sum sediment torque for rolling),

$$
\mathbf{T}_{S}=0
$$

Substitution of (A3)-(A5) into (A7) gives

$$
\psi_{b}=\tan ^{-1}\left(\frac{\psi_{B}-\sin \psi_{B} \cos \psi_{B}}{\sin ^{2} \psi_{B}}\right)
$$

The ratio $\lambda=b / B$ can be obtained from (A6) and (A8),

$$
\lambda \equiv b / B=\frac{1-\cos \left[\tan ^{-1}\left(\frac{\psi_{B}-\sin \psi_{B} \cos \psi_{B}}{\sin ^{2} \psi_{B}}\right)\right]}{1-\cos \psi_{B}}
$$

The ratio, $\lambda$, varies with the burial percentage $p_{B}=B / D$ mildly from near 0.4445 for $p_{B}=0$ and 0.4630 . Here, we take $\lambda=0.453$ in this study.

\section{Appendix B Dynamics of Rolling Object}

The drag force $\left(F_{d}\right)$ and lift force $\left(F_{l}\right)$ (see Appendix $C$ ) roll the object forward with the torque $T_{F}$ (Figure B1),

$$
\begin{aligned}
& T_{F}=F_{d}(D / 2+B / 2-b)+F_{l} \sqrt{b(D-b)} \\
& =\frac{1}{2} C_{d} \rho_{w} U^{2} L\left[(D-B)(D / 2+B / 2-b)+\frac{C_{l}}{C_{d}} D \sqrt{b(D-b)}\right]\left(1-\frac{u_{o}}{U}\right)^{2}
\end{aligned}
$$

The buoyancy force and added mass roll the object backward with the torque, $T_{B}=T_{w}+T_{a}$, 


$$
\begin{aligned}
& T_{B}=F_{w} \sqrt{b(D-b)}+F_{a}(D / 2+B / 2-b) \\
& =\frac{\pi}{4} g L D^{2}\left(\rho_{o}-\rho_{w}\right) \sqrt{b(D-b)}+\frac{d u_{o}}{d t} \rho_{w} \Pi(D / 2+B / 2-b)
\end{aligned}
$$

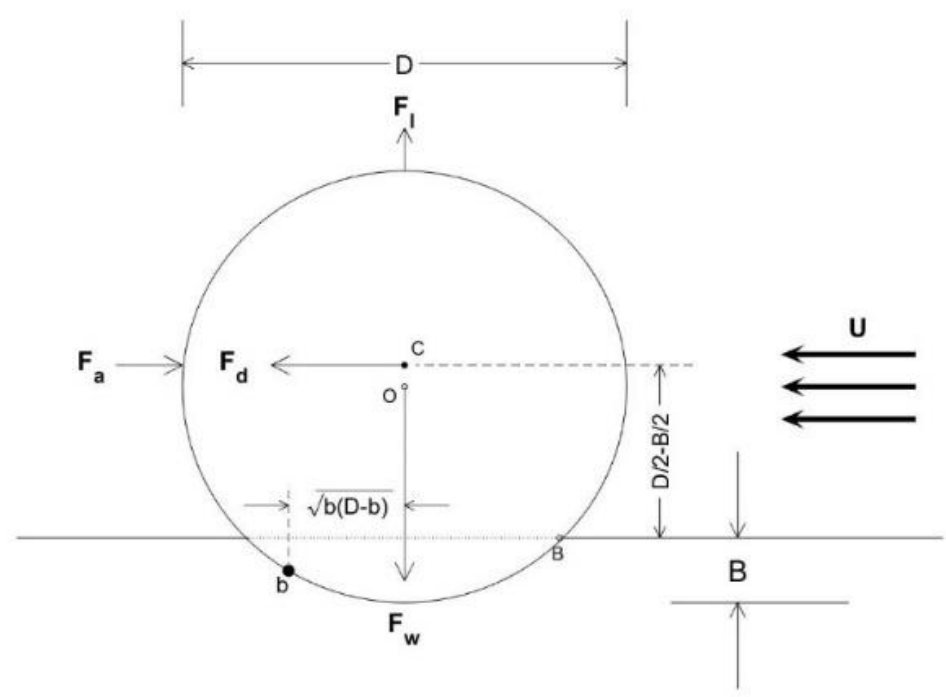

Figure B1. Forces and torques due to drag, lift, buoyancy, and added mass on a partially buried cylinder by combination of ocean currents and bottom wave orbital velocity $(U)$ perpendicular to the major axis of the cylinder.

When $T_{F}>T_{B}$ the object accelerates if it is in motion or starts to move if it is at rest $\left(u_{o}=0, d u_{o} / d t=\right.$ $0)$. When $T_{F}<T_{B}$ the object decelerates if it is in motion or keeps motionless if it is at rest. When $T_{F}=$ $T_{B}$ the object keeps velocity constant if it is in motion or keeps motionless if it is at rest. Thus, the threshold for the munition's mobility becomes

$$
T_{F}>T_{B}
$$

The acceleration-deceleration ratio is defined by

$$
\frac{T_{F}}{T_{B}}=\theta_{o p b}\left(1-\frac{u_{o}}{U}\right)^{2}
$$

where

$$
\begin{aligned}
& \theta_{o p b}=\frac{\theta_{0}}{\pi}\left[\frac{1-p_{b}}{\sqrt{p_{b}\left(1-p_{b}\right)}}\left(1+p_{B}-2 p_{b}\right)+2 \gamma\right], \\
& \theta_{0} \equiv\left[\frac{C_{d} U^{2}}{g D\left(S_{o}-1\right)}\right], \quad p_{b}=\frac{b}{D}, \quad S_{o}=\frac{\rho_{o}}{\rho_{w}}>1
\end{aligned}
$$

Here, $\theta_{o p b}$ is the object percentage burial Shields parameter based on $p_{b}$ [14]; and $S_{o}$ is the relative density of the object. For motionless munition $\left(u_{o}=0\right)$, the condition for the object to move is obtained through substituting (B4) into (B3) 


$$
\theta_{o p b}>1
$$

The corresponding moment of momentum equation of the rolling object is given by

$$
\left\{\begin{array}{cc}
I_{A} \frac{d \omega}{d t}=T_{F}-T_{B} & \text { if } p_{B}<0.5, \theta_{o p b}>1 \\
\omega=0, & \text { otherwise }
\end{array}\right.
$$

Substitution of $\left(T_{F}, T_{B}\right)$ in (B1) (B2) into (16) leads to

$$
\left\{\begin{array}{cc}
I_{A}^{*} \frac{d \omega}{d t}=T_{F}-\Pi\left(\rho_{o}-\rho_{w}\right) \sqrt{b(D-b)} & \text { if } p_{B}<0.5, \theta_{o p b}>1 \\
\omega=0, & \text { otherwise } \\
I_{A}^{*}=I_{A}+\left(\frac{D}{2}-b\right) \rho_{w} \Pi(D / 2+B / 2-b)
\end{array}\right.
$$

with

$$
I_{A}=I_{o}+\rho_{o} \Pi D^{2} / 4
$$

where $I_{o}$ is the rolling moment about the symmetric axis of the munition; $I_{A}$ is the rolling moment of munition about the point $b$ (see Figure B1) using the parallel axis theorem; $\Pi$ is the volume of the munition.

\section{Appendix C Drag, Lift, Buoyancy Forces, and Added Mass}

The drag force $\left(F_{d}\right)$, lift force $\left(F_{l}\right)$, buoyancy force $\left(F_{w}\right)$, and added mass $\left(F_{a}\right)$ exerted on the object for rolling by the perpendicular component, $U$, are given by

$$
\begin{aligned}
& F_{d}=\frac{\rho_{w} C_{d} U^{2} L(D-B)}{2}, \quad F_{l}=\frac{\rho_{w} C_{l} U^{2} L D}{2}, \\
& F_{w}=g\left(\rho_{o}-\rho_{w}\right) \Pi, \quad F_{a}=-\rho_{w} \Pi \frac{d u_{o}}{d t}
\end{aligned}
$$

where $\mathrm{g}=9.81 \mathrm{~m} / \mathrm{s}^{2}$ is the gravitational acceleration; $\rho_{w}=1,025 \mathrm{~kg} / \mathrm{m}^{3}$ is the density of seawater; $\rho_{o}$ is the density of the cylindrical object; $\left(C_{d}, C_{l}\right)$ are the drag and lift coefficients across-cylinder 's main axis with vortex shedding caused by the oscillating flow $(U)$ due to waves. If time averaged $U$ within a certain time period being used, the mean coefficients for drag and lift $\left(C_{d}, C_{l}\right)$, depending solely on the Reynolds number and aspect ratio (see Appendix D), can be used. Since the wave component (i.e., the bottom wave orbital velocity in $\mathbf{V}_{w}$ for the object model is computed from a linear wave model with the temporal resolution of 30 minutes, the mean coefficients for drag and lift are used. The vortex shedding from objects is neglected. Besides, the lift coefficient is less certain, we assume

$$
C_{l}=\gamma C_{d}
$$

where $\gamma$ is the ratio of lift coefficient versus drag coefficient with $\gamma$ being taken as value of 0.2 .

\section{Appendix D Drag Coefficient}

For cylindrical objects, the drag force is decomposed into along and cross axis components. The drag coefficient across-cylinder 's main axis $C_{d}$ depends on the Reynolds number,

$$
\operatorname{Re}=\frac{U D}{v}
$$


where $v=0.8 \times 10^{-6} \mathrm{~m}^{2} / \mathrm{s}$, is the sea water kinematic viscosity; $U$ is the horizontal water velocity perpendicular to the cylinder's main axis; and $D$ is the cylinder's diameter (see Figure 6). For An empirical formula is used to calculate $C_{d}$ [29],

$$
C_{d}=\left\{\begin{array}{cc}
1.9276+8 / \mathrm{Re}, & \text { if } \operatorname{Re} \leq 12 \\
1.261+16 / \mathrm{Re}, & \text { if } 12<\operatorname{Re} \leq 180 \\
0.855+89 / \mathrm{Re}, & \text { if } 180<\operatorname{Re} \leq 2000 \\
0.84+0.00003 \mathrm{Re}, & \text { if } 2000<\operatorname{Re} \leq 12000 \\
1.2-4 / \eta & \text { if } 12000<\operatorname{Re} \leq 150000, \eta \geq 10 \\
0.835-0.35 / \eta, & \text { if } 12000<\operatorname{Re} \leq 150000,2 \leq \eta<10 \\
0.7-0.08 / \eta, & \text { if } 12000<\operatorname{Re} \leq 150000, \eta<2 \\
1.875-0.0000045 \mathrm{Re}, & \text { if } 150000<\operatorname{Re} \leq 350000 \\
1 /(641550 / \operatorname{Re}+1.5), & \text { if } \operatorname{Re}>350000 .
\end{array}\right.
$$

where $\eta=L / D$, is the cylinder's aspect ratio.

\section{References}

1. SERDP, "Munitions in the Underwater Environment: State of the Science and Knowledge Gaps," White Paper. 〈https://www.serdp-estcp.org/Featured-Initiatives/Munitions-Response-Initiatives/Munitions-inthe-Underwater-Environment $\rangle, 2010$.

2. Bennett, R.H. Mine Burial Prediction Workshop Report and Recommendations. Prepared for ONR. Technical Report Number SI-0000-02. 2000, 1-21..

3. Chu, P.C. Mine impact burial prediction from one to three dimensions. Appl. Mech. Rev., vol. 62, no. 1, 010802, pp.25, 2009

4. Chu, P.C., Fan, C.W. Evans, A.D. Gilles, A.F. Triple coordinate transforms for prediction of falling cylinder through the water column. J. Appl. Mech., vol. 71, pp. 292-298, 2004.

5. Chu, P.C. Gilles, A.F., Fan, C.W. Experiment of falling cylinder through the water column. Exp. Therm. Fluid Sci., vol. 29, pp. 555-568, 2005.

6. Chu, P.C., Fan, C.W. Mine impact burial model (IMPACT35) verification and improvement using sediment bearing factor method. IEEE J. Ocean. Eng., vol. 32, pp. 34-48, 2007.

7. Chu, P.C., Fan, C.W. Pseudo-cylinder parameterization for mine impact burial prediction. J. Fluids Eng., vol. 127, pp. 1515-1520, 2005.

8. Chu, P.C., Fan, C.W. Prediction of falling cylinder through air-water-sediment columns. J. Appl. Mech., vol. 73, pp. 300-314, 2006.

9. Chu, P.C., Fan, C.W., Calantoni, J., Sheremet A. Prediction of mobility and burial of object on sandy seafloor. IEEE J. Ocean. Eng. (conditionally accepted).

10. Deltares, 2019a: Delft3D-Flow-Simulation of multi-dimensional hydrodynamic flows and transport phenomena, including sediments, User Manual. https://content.oss.deltares.nl/delft3d/manuals/Delft3DFLOW_User_Manual.pdf.

11. Deltares, 2019b: Delft3D-Wave-Simulation of short-crested waves with SWAN, User Manual. https://content.oss.deltares.nl/delft3d/manuals/Delft3D-WAVE_User_Manual.

12. Booij, N.; Ris, R.C.; Holthuijsen, L.H. A third-generation wave model for coastal regions: 1. Model description and validation. J. Geophys. Res. 1999, 104, 7649-7666. 
13. Calantoni, J., Staples, T., Sheremet, A. Long time series measurements of munitions mobility in the wavecurrent boundary layer. Interim Report, US Strategic Environmental Research and Development Program, Project MR-2320, pp. 48, 2014.

14. Traykovski, P., Austin, T. Continuous monitoring of mobility, burial, and re-exposure of underwater munitions in energetic near-shore environments. Final Report, US Strategic Environmental Research and Development Program, Project MR-2319, pp. 44, 2017.

15. Friedrichs, C.T. Rennie, S.E., Brandt, A. Self-burial of objects on sandy beds by scour: a synthesis of observations. In: Harris, J.M., Whitehouse, R.J.S. (Eds.), Scour and Erosion. CRC Press, ISBN: 978-1-13802979-8, pp. 179-189, 2016.

16. S.E. Rennie, Brandt, A., Friedrichs, C.T. Initiation of motion and scour burial of objects underwater. Ocean Eng., vol. 131, 282-294, 2017.

17. Pessanha, V.S., Chu, P.C., Gough, M.K., Rapid sediment accretion near Panama City during passage of two consecutive cold fronts in early May 2013. J. Oper. Oceanogr. (in review).

18. NOAA/NGDC. Northern Gulf 1 arc-second MHW Coast Digital Elevation Model. Available online: https://catalog.data.gov/dataset/northern-gulf-coast-digital-elevation-model156ed (accessed on 17 December 2018).

19. ECMWF. ERA5 Reanalysis (0.25 Degree Latitude-Longitude Grid). Research Data Archive at the National Center for Atmospheric Research, Computational and Information Systems Laboratory, Boulder, CO. Available online: https://rda.ucar.edu/datasets/ds633.0 (accessed on 3 July 2019).

20. Roelvink, D.; Reniers, A. A guide to modeling coastal morphology. World Science Publishing Co. Pte. Ltd.: Singapure, 2012; pp. 3-16.

21. Wiberg, P.L., Sherwood, C.R. Calculating wave-generated bottom orbital velocities from surface wave parameters. Compt. Geosci., vol. 34, 1243-1262, 2008.

22. Kamke, E. Differentialgleichungen: Losungsmethoden und Losungen, I, Gewohnliche Differentialgleichungen," B. G. Teubner, Leipzig, 1977.

23. Nielsen, P. Coastal Bottom Boundary Layers and Sediment Transport. Advanced Series on Ocean Engineering 4. World Scientific, Singapore, pp.324, 1992.

24. Whitehouse, R. Scour at Marine Structures: a Manual for Practical Applications, Thomas Telford Publications, London, pp. 198, 1998.

25. Sumer, B.M., Truelsen, C., Sichmann, T., Fredsøe, J. Onset of scour below pipelines and self-burial. Coast. Eng., vol 42, pp. 313-335, 2001.

26. Demir, S.T., García, M.H., Experimental studies on burial of finite length cylinders under oscillatory flow. J. Waterw. Port. Coast Ocean Eng. ASCE vol 133 (2), pp. 117-124, 2007.

27. Cataño-Lopera, Y.A., Demir, S.T. García, M.H. Self-burial of short cylinders under oscillatory flows and combined waves plus current. IEEE J. Ocean. Eng., vol 32, pp. 191-203, 2007.

28. Trembanis, A.C., Friedrichs, C.T., Richardson, M.D., Traykovski, P., Howd, P.A., Elmore, P.A., Wever, T.F. Predicting seabed burial of cylinders by wave-induced scour: application to the sandy inner shelf off Florida and Massachusetts. IEEE J. Ocean. Eng., vol 32, pp. 167-183, 2007.

29. Rouse, H. Fluid Mechanics for Hydraulic Engineers. $1^{\text {st }}$ Ed., Mcgraw-Hill Book Company Inc., New York, pp. 422, 1938. 